\title{
QUANDO O SONHO CESSA E A ILUSÃO PSICOPEDAGÓGICA NOS INVADE, A ESCOLA ENTRA EM CRISE. NOTAS COMPARATIVAS ARGENTINA, BRASIL, FRANÇA
}

\author{
WHEN DREAM CEASES AND THE PSYCHOPEDAGOGICAL ILLUSION INVADES US, \\ SCHOOL ENTERS CRISIS. \\ COMPARATIVE NOTES ARGENTINA, BRAZIL, FRANCE \\ CUANDO EL SUEÑO CESA Y LA ILUSION PSICOPEDAGOGICA INVADENOS, LA \\ ESCUELA ENTRA EN CRISIS. \\ ESBOZO COMPARATIVO ARGENTINA, BRASIL, FRANCIA
}

\section{RESUMO}

Leandro de Lajonquière ${ }^{1}$

A partir das referências críticas de Freud à pedagogia, apresenta-se a tese de que, embora todo ideário pedagógico se estruture a partir de um ponto cego, qual seja, o desconhecimento do desejo em causa no laço educativo escolar, cabe a toda criança inverter a demanda adulta para conquistar para si um lugar de palavra numa história e assim adentrar no conhecimento. No entanto, essa operação bem pode reclamar um trabalho psíquico suplementar por parte da criança dependendo de como o sistema pedagógico se enderece a ela. 0 endereçamento adulto deve interpelar a criança como aluno para que assim ela possa se lançar dignamente ao aprendizado escolar. A eficácia simbólica dessa interpelação pedagógica foge ao gabarito do desenvolvimento das competências docentes e, portanto, a todo programa de formação profissional. O esboço de uma comparação entre os sistemas escolares franceses, brasileiros e argentinos, e suas transformações na história, permite precisar, por um lado, o valor heurístico da noção de ilusão psicopedagógica (LAJONQUIERE, 1997) e, por outro, afirmar que cada um deles desconhece, de forma singular, que todo processo massivo de escolarização bem-sucedido é animado pelo sonho moderno de uma escola para todos sem distinção de origem familiar.

PALAVRAS-CHAVE: Formação de professores. Escola moderna. Ilusão psicopedagógica.

\begin{abstract}
From Freud's critical references to pedagogy, it is presented the thesis that, although all pedagogical ideals are structured from a blind point, that is, the ignorance of the desire in question in the school education bond, it is up to every child to reverse the adult demand to conquer for itself a place of word in a history and thus to get into knowledge. However, this operation may claim additional psychic work on the part of the child depending on how a pedagogical system addresses itself to him or her. Adult addressing should challenge the child as a learner so he or she can appropriately jump to school learning. The symbolic efficacy of this pedagogical interpellation goes beyond the feedback of the development of teaching competences and, therefore, to any professional training program. The sketch of a comparison between the French, Brazilian and Argentine school systems and their transformations in history makes it possible to specify, on the one hand, the heuristic value of the notion of psychopedagogical illusion (LAJONQUIERE, 1997) and, on the other hand, to affirm that each one of them ignores in a singular way that every massive process of successful schooling is animated by the modern dream of a school for all without distinction of family origin.
\end{abstract}

KEYWORDS: Teacher training. Modern school. Psychopedagogical illusion.

\footnotetext{
${ }^{1}$ Doutor em Educação - Universidade Estadual de Campinas (UNICAMP) - Campinas, SP - Brasil. Docente Universidade de São Paulo (USP) - São Paulo, SP - Brasil. Docente - Universidade Paris 8. Membro fundador do LEPSI - USP. E-mail: Idelajon@usp.br
}

Submetido em: 06/02/2018- Aceito em: 24/07/2018

(C) ETD- Educação Temática Digital Campinas, SP $\quad$ v.21 $\quad$ n.2 $\quad$ p.297-315 abr./jun. 2019




\section{RESUMEN}

A partir de referencias críticas de Freud a la pedagogía, desarrollase la tesis de que, si bien todo ideario pedagógico estructurase a partir de un punto ciego como el desconocimiento del deseo en causa en el lazo educativo escolar, todo niño debe invertir la demanda adulta para conquistar para sí mismo un lugar de palabra en una historia y de esa forma lanzarse al conocimiento. Sin embargo, esa operación bien puede requerirle un trabajo psíquico suplementar dependiendo de cómo un sistema pedagógico le dirija la palabra a él. La palabra adulta debe interpelar el niño como aluno para que así él pueda comprometerse dignamente en el aprendizaje escolar. La eficacia simbólica de esa interpelación pedagógica no está sujeta al desarrollo de competencias docentes y, por lo tanto, no responde a los programas de formación profesional. El esbozo de una comparación entre los sistemas escolares franceses, brasileños y argentinos y sus transformaciones en la historia, permite precisar, por un lado, el valor heurístico de la noción de ilusión psicopedagógica (LAJONQUIERE, 1997) y, por el otro, afirmar que cada uno de ellos desconoce a su manera que toda escolarización masiva exitosa está animada de hecho por el sueño moderno de una escuela para todos sin distinción de origen familiar.

PALABRAS-CLAVE: Formación de profesores. Escuela moderna. Ilusión psicopedagógica.

\section{INTRODUÇÃO}

As controvérsias sobre a formação de professores quando pareciam ter sido medianamente encerradas graças à construção de um certo consenso, voltam novamente a ocupar o centro dos debates pedagógicos. A razão para tamanha insistência da questão seria a crise pela qual atravessa costumeiramente a educação. A dita crise da educação faz com que a resposta considerada adequada aos desafios próprios de uma época em matéria de formação profissional, não o seja mais. O que se entende por crise é sintomático no tempo e na geografia nacional, ou seja, as mudanças e reformas implementadas estão sempre em função do momento histórico de uma nação determinada. No entanto, há tempo se impôs como líquida e certa, além dos particularismos nacionais, a ideia de estarmos a atravessar uma crise na educação que reclama a formação de um outro profissional, pois, este de hoje, formado um tempo antes, já não mais apresentaria competências à altura das novas circunstâncias.

A comparação entre os sistemas escolares nacionais, o rendimento dos alunos e os modelos de formação profissional docente não é novidade. Embora os estudos comparativos não devam se reduzir a simples mensurações, hoje virou hábito divulgar na grande imprensa, estatísticas e rankings diversos em matéria de escolarização, planos de carreira profissional, salários e bônus. Infelizmente, o foco não é no sentido de ver como certas sociedades 'pensam' a questão escolar na sua complexidade, à diferença de outras talvez distantes geograficamente ou simplesmente vizinhas, falantes de uma mesma língua ou não, mais ou menos irmanadas na guerra ou na paz. Estas comparações poderiam ser esclarecedoras de quais são as ideias que imperam nos debates pedagógicos, que enquadram as experiências escolares das crianças, e animam as iniciativas de formação profissional. Assim, as análises comparativas possibilitariam a um país 'ver-se' um pouco diferente de como está acostumado a ver a si mesmo todos os dias. Um país poderia, graças ao esforço de se elucidar como é que

(C) ETD- Educação Temática Digital Campinas, SP $\quad$ v.21 $\quad$ n.2 $\quad$ p.297-315 abr./jun. 2019


um outro equaciona a questão escolar, 'pensa' a sua própria 'crise', e formula soluções à sua maneira, aprender indiretamente sobre os seus próprios rumos na escolarização de crianças e de jovens, sobre seus acertos e impasses na matéria. Poderia, nessa direção, chegar a se convencer da insistência irredutível de certas condições de possibilidade da educação, que bem deveriam ser chamadas de estruturais. Iniciativas nesse sentido poderiam funcionar como um antídoto contra dois hábitos bem costumeiros: ora a importação acrítica de modelos pedagógicos prontos considerados ideais, ora a tentativa de aventurar-se na produção da grande invenção pedagógica nunca antes pensada na história da humanidade, capaz de propulsar o país ao pódio dos feitos pedagógicos.

O império nos imaginários pedagógicos nacionais de certas ideias em detrimento de outras é revelador da circulação de determinadas tramas conceituais, em sintonia com diversos momentos da história e da política nacional, nos quais o fator contingencial tampouco deixa de estar presente. Assim sendo, alguns países primam por certas teorizações psicológicas, filosóficas e sociológicas em detrimento de outras. No entanto, os imaginários pedagógicos dizem também de idiossincrasias nacionais não tão claras e distintas. Para um psicanalista, dizem particularmente de como é vivida a diferença entre adultos e crianças, de como é que 'se pensa' que estas deixam de sê-lo com o tempo para ficarem grandes, em suma, dizem do lugar singular que as crianças ocupam nas fantasias e sonhos adultos. Estes fincam suas raízes na história de vida singular do povo sonhador. Porém, além de contingências corriqueiras, os imaginários pedagógicos se estruturam, em última instância, em torno de um ponto cego que escapa à simbolização, assim como Freud dizia que todo sonho perdia-se numa espécie de umbigo insondável. Dessa forma, todo imaginário pedagógico diz para um psicanalista como o mundo adulto experimenta e sonha sua relação contraditória com a criança. Sobre a relação à criança, os adultos, tanto querem saber quanto não querem saber, que não se pode saber que não há saber 'sobre' ela (LAJONQUIERE, 1999).

O irredutível 'não querer saber' de que 'não há saber sobre' a nossa relação à criança, faz com que o mundo adulto se iluda pensando que as formulações pedagógicas de uma época, embora objeto de discussões filosóficas, políticas ou científicas de qualquer teor, estejam sempre bem fundadas em ideias claras e distintas. Por outro lado, para um psicanalista, essa insistência em 'não querer saber' não é sem consequências para as crianças. De fato, Freud afirmou em Mal-estar na civilização (1929) que "a educação se conduz como se enviasse as crianças numa expedição polar vestidas com roupas de verão e equipadas com os mapas dos lagos italianos" (p. 3060). No entanto, as crianças conseguem fugir de semelhante empresa turística polar. Elas sobrevivem às suas escolas, e aos seus professores, sempre mais ou menos competentes segundo o discurso pedagógico oficial de época. Mais ainda, aprendem não poucas coisas graças ao fato de as terem frequentado. Isso não deve nos surpreender, pois a cada criança cabe inverter, não sem esforço, demandas educativas

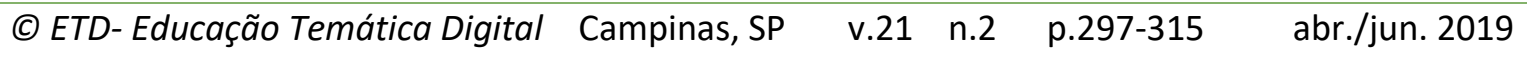


adultas mais ou menos enlouquecidas, ou não. Como tal coisa é possível? De fato, tudo depende das chances de uma criança vir a situar o desejo no horizonte da experiência educativa, isto é, a castração no Outro. Essa operação cobra de toda criança uma singular implicação subjetiva. Porém, também é verdade que há sistemas escolares menos perversos que outros, no sentido de que, o preço que exigem da criança, para ela conseguir inverter a demanda educativa, não Ihe seja psiquicamente desproporcionado (LAJONQUIERE, 1997, 1999, 2009, 2017).

A formação profissional de docentes e suas supostas urgências para enfrentar a crise do momento são então, peças constituintes de todo imaginário pedagógico e, portanto, guardam íntima ligação com a forma que temos de pensar e de sonhar a experiência escolar das crianças, as suas condições de possibilidade, as suas vicissitudes, bem como os seus pontos de impasse. Para um psicanalista, toda tentativa de tratar separadamente os diversos elementos que tornam possível a experiência escolar de uma criança, como se pudessem ser formulados equacionamentos técnico-metodológicos específicos para cada 'problema', está a serviço do desconhecimento da impossibilidade de saber sobre a relação adulto-criança, e portanto, acaba colocando em risco a factibilidade da educação para uma criança. Em outras palavras, acaba instalando as chances da educação virar um fato de difícil acontecimento, conforme a formulação por mim feita há vinte anos (LAJONQUIERE, 1997, 1999).

\section{SONHO DE UMA ESCOLA PARA TODOS E A CRISE NA EDUCAÇÃO}

Há conhecimentos diversos no interior do campo da palavra e da linguagem. Por isso mesmo, são passíveis de transmissão por aqueles que a eles já foram sujeitados - os mestres no assunto - à esses outros que ainda os ignoram - os discípulos. Os dispositivos escolares foram inventados com o intuito preciso de possibilitar essa transmissão, possibilitar esse encontro entre uns e outros, entre professores e alunos. A transmissão é sem garantias, pois não é um processo natural como de hábito se pensa. Não se aprende por cópia, imitação ou repetição de modelos. O que não quer dizer que não se possa copiar nem imitar. De fato, há sistemas escolares que ainda hoje fazem da outrora omnipresente cópia um de seus pilares. Mas isso pouco importa. Os estudos psico-epistemológicos de Jean Piaget já permitiram pensar que o 'transmitido' foi de fato reconstruído cognitivamente em-si, e para-si, pelo sujeito, que simplesmente pensava estar copiando sem saber ${ }^{2}$. Por outro lado, e nessa mesma direção, um pouco mais de um século de psicanálise permite afirmar que aquilo que se aprende, seja na escola ou fora dela, é aquilo que de fato prende o sujeito. Em suma, o sujeito

\footnotetext{
${ }^{2}$ Assim sendo, o fato de copiar ou reescrever um ditado, tentando não repetir as faltas de ortografia, nunca nada garantiram em matéria de aprendizagem, mas temos de convir que tampouco mataram ninguém. Já não se pode dizer o mesmo do fato de tê-los banido de nossas escolas. Até que ponto esse gesto em nome da renovação pedagógica não acabou comprometendo o desdobramento do roteiro escolar articulado em torno da escrita?
}

(C) ETD- Educação Temática Digital Campinas, SP $\quad$ v.21 $\quad$ n.2 $\quad$ p.297-315 abr./jun. 2019 
aprende aquilo que o apreende. E isso também se dá sem o sujeito saber. Aprende-se sem saber, pois não são paradoxalmente os conhecimentos que prendem o sujeito, mas o "desejo" em causa no ato de transmissão. A questão é, então, até que ponto os sistemas escolares possibilitam ou não o desdobramento operativo de um desejo nos encontros entre adultos e crianças, ou entre mestres e discípulos circunstanciais. Quando assim acontece, o sistema funciona; quando não, as condições de possibilidade do aprender escolar embaralham-se a ponto de o fato de as crianças apre(e)nderem os conhecimentos ensinados ou mostrados se tornar algo de difícil acontecimento.

É interessante analisar como é que cada país imagina ou fantasia o desdobramento da cena do encontro entre o mestre e o candidato a discípulo. Nesse sentido, uma rápida confrontação entre os sistemas escolares brasileiro, francês e argentino lança pistas de como é que, em cada um deles, certa dramática escolar passa a ser possível em detrimento de outras. Quando do império do sonho de que a universalização da escolarização era não só possível, senão que também devia ser buscada deliberadamente, nos finais do século XIX, os dispositivos escolares supunham que a 'partida' era jogada a partir da simples movimentação de duas peças sobre o tabuleiro, quais sejam - a "interpelação" da criança como aluno (ALTHUSSER, 1976), e a simples apresentação dos conhecimentos por parte do mestre. Este é o jogo pedagógico ou forma escolar que passou a ser chamado tradicional. Ele já era a razão de ser do ideário pedagógico jesuítico. Quando do advento de uma escola embalada no sonho de uma escola para todos, no instar do espírito universalista republicano, esse jogo foi simplesmente laicizado para assim continuar a vigorar. Nesse sentido, a competência docente de um professor implicava saber sustentar essa operação simbólica eficaz de interpelação subjetiva, bem como certa mestria dos conhecimentos a serem ensinados. Ele tanto funcionou bem como ainda funciona, embora mudem os ouropéis imaginários da forma de se interpelar as crianças em alunos e/ou os conhecimentos veiculados. Entretanto, o funcionamento não obedece às razões conscientemente esgrimidas nos grandiloquentes projetos pedagógicos de hoje em dia. Justamente, a chave da "eficácia simbólica" (LEVISTRAUSS, 1958) inerente à interpelação pedagógica da criança em aluno, não estriba, conforme elucidado a partir da psicanálise, em nenhuma competência técnica individual do professor passível de ser metodicamente aprendida (LAJONQUIERE, 2011, 2013). Em suma, esta singular competência profissional (sic) transcende, infelizmente, o escopo de todo curso de formação de professores.

O sistema escolar francês tem mudado no século, mas, embora o consenso pedagógico de outrora tenha se diluído, é possível dizer que nele ainda impera o tradicional espírito do jogo jogado pelos jesuítas: eu apresento o saber e você se dá o trabalho de apre(e)nder, pois, ninguém lhe resiste, e caso você venha a não conseguir, isso mostra que seu esforço não esteve à altura da tarefa. Como curiosidade, lembremos que nas escolas

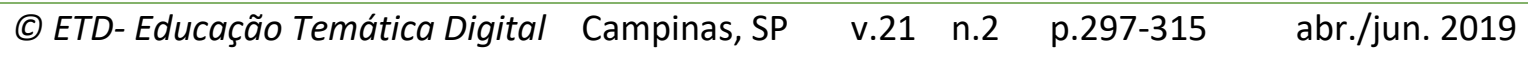


francesas, as crianças ainda copiam, recitam e fazem sistematicamente ditados, que uma vez corrigidos são recopiados. Assim como no Brasil e na Argentina, na França também se repete que a educação, e em particular a escolar, está em crise, e que, para se convencer disso, bastaria comparar o pouco que as crianças sabem hoje com aquilo que as gerações anteriores aprendiam. Mais ainda, desde o cidadão da rua até o jornalista de televisão citam estatísticas internacionais que situam os rendimentos escolares franceses numa posição inferior àquela que deveria ser conforme o suposto destino reservado a França pela história (sic). Pouco importa conferir se os franceses têm ou não razão de reclamar da 'crise'. Perante a dita, eles reduplicam a oferta cognitiva sem chegar a suspeitar que os conhecimentos por si só não colam, não apre(e)ndem os sujeitos. A confiança no poder pedagógico dos conhecimentos é grande, portanto, a explicação não pode não convencer o 'outro', destinatário de um ensino mais ou menos sempre magistral, de um mestre às vezes pedante.

A escola francesa, à diferença da brasileira e da argentina, não se estrutura em torno da "ilusão psicopedagógica". No entanto, que ainda hoje ela não seja tomada pelo império dessa ilusão, não quer dizer que a crença, tanto na possibilidade quanto na necessidade de se ajustar ou adequar a intervenção adulta às capacidades da criança, no intuito de fazer 'colar' os conhecimentos, não desponte no horizonte do imaginário pedagógico francês atual. A ilusão psicopedagógica alça a sua voz de tempos em tempos, aqui e lá, mas sem vir a ocupar o centro da cena e dar as cartas como se diz. Curiosamente, ela se faz presente no meio universitário dedicado às ciências da educação, cujos representantes reclamam precisamente da impermeabilidade refratária do sistema nacional de escolarização às recomendações expertas em matéria psicopedagógica. Diferentemente do Brasil onde toda "novidade cientifica" produzida na universidade é rapidamente absorvida, ora pelas redes de ensino, ora pelas escolas privadas, a escola francesa é relativamente impermeável. No imaginário social, bem como particularmente no interior do sistema escolar francês, ainda prima hoje a ideia de que, em princípio, todo mundo aprende se confrontado a um ensino digno desse nome. Essa dicotomia pedagógica é conhecida na França como o debate entre os "republicanos", partidários da transmissão de saberes, e os "pedagogistas" propulsores da revisão da forma escolar tradicional. Em poucas palavras, o debate é vivido como sendo o dilema entre a "transmissão" e o "aprender" que, por sinal, acaba se superpondo às vezes ao debate político entre direita e esquerda (BLAIS, GAUCHET, OTTAVI, 2014) ${ }^{3}$. Assim sendo, a escola francesa não peca por defeito educativo, mas por excesso pedagógico (LAJONQUIERE, 1999). Embora

\footnotetext{
${ }^{3}$ A redação deste texto tinha sido concluída, quando os jornais divulgaram (09/01/18) que o ministro de educação do governo do presidente $\mathrm{E}$. Macron vinha de instalar uma comissão pluridisciplinar de expertos com vistas a promover o debate sobre o ensino escolar. Fato curioso, às primeiras reações contrarias e automáticas à iniciativa, tanto dos partidários da 'transmissão' quanto daqueles do 'aprender', seguiram-se no decorrer dos dias manifestações de interesse pela iniciativa ministerial na impressa tanto de direita quando de esquerda. 0 tempo ainda dirá ...
}

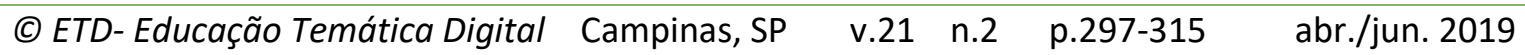


obviamente os resultados finais em matéria de escolarização não sejam idênticos, vistas as respetivas magnitudes de cultura letrada, em última instância acabam dando na mesma, ou seja, cada um dos três sistemas pedagógicos faz, à sua maneira, ouvidos moucos ao retorno do recalcado no laço educativo - o desejo - portanto, o alerta freudiano, estampado no Malestar da civilização (1929) não perde atualidade.

O processo argentino de escolarização massiva toma corpo em 1884 graças à promulgação da Lei 1420, dita da educação comum, laica, gratuita e obrigatória, e, à determinação governamental de escolarizar sem trégua os filhos dos imigrantes - esses outros falantes de outras línguas que não o castelhano nacional - que triplicaram a população nacional no curto espaço de duas décadas. Essa aposta vingou, pois, por um lado, o país virou monolingue conforme o esperado pelas elites governamentais na época e, talvez, como também esperado por não poucos dos próprios recém-chegados, que esperavam se esquecer da língua de origem, e dessa forma, tomar distância da vida mais ou menos atribulada numa primeira língua. Por outro, a aposta também vingou, pois, a Argentina passou rapidamente a ocupar o pódio dos países letrados. Esse processo não se deu sem a instituição de uma narrativa nacional, não só povoada por uma série de heróis nacionais recriados pela historiografia, na época recentemente constituída, mas também pela introdução na história de um novo personagem, 'o gaúcho', produzido e elevado pela estética literária à categoria de ancestral idiossincrático desses argentinos novos, seja por terem chegado por barco ou nascido em solo pátrio. Esse personagem passou, então, a ocupar um lugar equivalente aos gaulois no romance nacional francês da Terceira República. O curioso é que, na época, nem os responsáveis governamentais nem os especialistas argentinos, reunidos por ocasião do Primeiro Congresso Pedagógico (1882), à iniciativa desse "incansável da espada, da pena e da palavra", ${ }^{4}$ que fora Domingo Faustino Sarmiento, lamentavam-se de crise educativa alguma. O desafio perante o qual essa geração de políticos e intelectuais se deparava era tecer uma narrativa nacional a partir de retalhos de histórias díspares. A situação era relativamente equivalente à francesa, embora as unificações linguística e territorial estivessem já em curso na França. Não propriamente a ideia de que se podia conviver num espaço republicano e democrático - esta ainda devia ser emplacada, e para tanto, a laicidade da vida societária era peça indispensável. Ao contrário, na Argentina, o universalismo republicano se impôs logo. É verdade que, a que tomou corpo nos finais do século XIX foi uma república oligárquica, mas é verdade também, que a escola pública, gratuita e obrigatória que ela emplacou, veio a contribuir para o seu próprio perecimento 5 .

\footnotetext{
${ }^{4}$ Referência aos termos usados no Hino a Sarmiento, de Leopoldo Corretjer (1862-1941).

${ }^{5}$ De fato, sem a universalização da escola, nunca teria sido possível a conquista do voto secreto e universal, responsável pela eleição democrática do primeiro governo de cunho popular na historia nacional - o de Hipólito Yrigoyen (1916-1922).
}

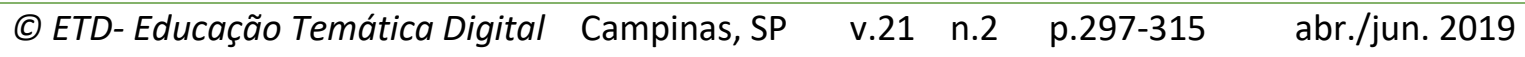


No sempre lembrado texto A Crise na Educação (1958), a filósofa Hannah Arendt afirmou serem os Estados Unidos de América, à diferença dos velhos países europeus, uma boa ilustração de como a universalização do processo de escolarização e sua crise implicavam uma dimensão política. Pessoalmente, creio que o mesmo raciocínio também se aplica à Argentina e ao Brasil, não só dos finais do século XIX, mas também aos países que são hoje em dia. Aliás, a crise na educação à la française também ilustra, assim como os EUA no raciocínio de Arendt, a dimensão política de se acolher na escola esse 'outro' dos dias de hoje, que é a criança de famílias recentemente instaladas na França.

O consenso pedagógico argentino manteve-se mais ou menos inalterado até a década de noventa do século passado. Será o governo Carlos Menen (1989-1999) quem promoverá uma grande reforma do universo escolar e de seu funcionamento. A centenária Lei 1420 foi abrogada dando lugar assim à desregulação da oferta escolar de estado. Ao mesmo tempo, o governo instaurou, pela primeira vez, no imaginário social, a suspeita generalizada de que os docentes não sabiam mais ensinar àquelas crianças diferentes àquela época, pois, reclamavam uma outra forma pedagógica de se ensinar. Desse modo, o governo fez emplacar a ideia de que se fazia necessário reinventar a escola a partir de novos parâmetros pedagógicos de cunho científico, bem como a formação docente com vistas a desenvolver novas competências profissionais. Assim, a chamada pedagogia construtivista, nomeada de 'inspiração piagetiana', veio a alterar tanto a clássica cena escolar quanto a formação de professores. Enfim, instalou-se de vez no horizonte pedagógico a ideia que, se a escola argentina não funcionava mais como era esperado, isso constituía uma crise na educação atrelada a um roteiro escolar incapaz de considerar a nova realidade psicossocial das crianças. A reforma pedagógica propulsada pelo governo Menen transformou a cena escolar dita tradicional. A transmissão de conhecimentos passou a requerer uma didática singular, capaz de possibilitar uma comunicação com a realidade psicossocial da criança ou do jovem, exigindo, portanto, novas competências profissionais. $O$ 'outro' destinatário do ensino, é por diversas razões, suposto ser refratário aos saberes escolares, bem como estes já não seriam mais transmissíveis per se.

Já no Brasil, nesses mesmos anos da década de noventa, o governo de Fernando Henrique propulsou uma reforma pedagógica no mesmo estilo à do país vizinho. Os especialistas no governo brasileiro trabalharam com o mesmo postulado pedagógico dos argentinos, que por sinal era o mesmo dos pedagogos do governo da Espanha, de que a educação escolar é possível quando a intervenção adulta se ajusta ou se adapta à realidade psicossocial da criança e do jovem (sic). Esse tal ajuste é por sua vez possível, se a prática pedagógica for parametrizada pelos elementos aportados pelos estudos piagetianos e vigotskianos sobre a aprendizagem e o desenvolvimento das capacidades psicobiológicas da criança. Esses foram considerados na época não só como sendo os mais pertinentes do ponto

\begin{tabular}{|c|}
\hline (c) \\
\hline
\end{tabular}


de vista científico para se elucidar o processo de aprendizagem humana, mas também passíveis de serem traduzidos ou transpostos à cena escolar como parâmetros de intervenção pedagógica. Nessa perspetiva, todo docente deveria ser formado no manejo desses novos parâmetros científicos com vistas, então, a adequar ou ajustar o ensino dos conhecimentos, sob pena de que eles não venham a serem apre(e)ndidos pelos alunos.

Ambas as reformas pedagógicas promoveram a deflação, tanto dos saberes escolares, quanto do estofo da palavra docente, e assim, acabaram por embaralhar as condições de possibilidade de uma experiência escolar que se preze. De agora em diante, de nada mais serve multiplicar os encontros entre mestres que sabem e candidatos a discípulos conforme a tradição pedagógica. Isso constitui um desperdício sabido de antemão. A razão escolar está atrelada à parametrização científica da intervenção pedagógica em consonância com o estado suposto das capacidades psicobiológicas da criança. Essa ideia faz às vezes do novo postulado responsável pelo reordenamento total do imaginário pedagógico hegemônico, e foi por nós chamada de ilusão psicopedagógica (LAJONQUIERE, 1997).

A proposta de falarmos, a fins dos anos noventa, em termos de ilusão, nos possibilitava não entrarmos na discussão estabelecida na época, de, se a tradução pedagógica de certas teses era ou não conforme os espíritos piagetianos ou vigotskianos. Pretendíamos deixar essa discussão restrita ao interior de cada um desses campos de estudos psicológicos. Como psicanalista, interessava-nos, no entanto, assinalar que o novo postulado pedagógico era uma ilusão no sentido freudiano, ou seja, uma crença animada por um desejo (FREUD, 1927). O desafio passava a ser então, o de elucidar de que desejo se trata e quais os efeitos produzidos no laço educativo pela colocação em ato da ilusão psicopedagógica. Esse desejo que animava a ilusão naturalista na educação foi qualificado de um desejo de não desejar, e a primeira tentativa de elucidar seus efeitos deletérios em matéria educativa deu origem ao livro "Infância e ilusão Psicopedagógica: escritos de psicanálise e educação" (LAJONQUIERE, 1999).

Hoje em dia, devido ao império de determinado reducionismo neuronal, daria a impressão de que a ilusão psicopedagógica perdeu terreno no imaginário pedagógico brasileiro. A criança não seria mais um ser psicossocial ou biopsicossocial. Agora, a ideia que reordena o discurso pedagógico seria aquela que reduz de vez a criança a um acúmulo de neurônios. Pode ser que assim seja, porém, a ilusão psicopedagógica continua incólume. Esta é a crença de que educar é desenvolver, 'puxar', 'fazer crescer', 'fazer vingar' de forma ajustada e/ou harmoniosa, aquilo que se supõe que a criança traz consigo (no seu organismo) para dentro da cena educativa. Isso suposto, trazer o neurônio é uma capacidade de 'vir a ser', que vingará na medida de sua integridade. Por sua vez, para se garantir esta última suposta detentora da chave do aprender infantil, administram-se os remédios necessários, bem como esse gesto é tido como parte integrante da educação. A receita do remédio passa agora a fazer parte da iniciativa educativa em si mesma. Por outro lado, poder-se-ia também

\begin{tabular}{|c|}
\hline (c) \\
\hline
\end{tabular}


dizer que a ilusão psicopedagógica não imperava antes do estabelecimento dos Parâmetros Curriculares Nacionais. É verdade que no Brasil, nos anos noventa, os saberes psicológicos gozavam de verdadeiro prestígio. Nessa época, por exemplo, consolida-se o campo profissional psicopedagógico. No entanto, há outros períodos nos quais o 'raciocínio sociológico' ocupa o lugar do 'psicológico'. Porém, isso tampouco abalou, abala ou abalará o império da ilusão psicopedagógica, que consiste na crença de que tanto é possível quanto necessário, se adaptar a intervenção à realidade social da criança, tida como determinante ou condicionante do que ela poderá apre(e)nder ${ }^{6}$. Essa realidade se exprime na posse pela criança de certas capacidades de 'vir a ser', com as quais a intervenção pedagógica deverá entrar em comunicação se quisermos que ela venha a apre(e)nder aquilo a ser ensinado.

Dessa forma, conforme os momentos históricos, o horizonte imaginário pode estar dominado ou pelos saberes psicológicos, ou pelos neurológicos, ou pelos sociológicos. Isso pouco importa: a ilusão psicopedagógica pode continuar a imperar. Ou seja, da crença de que tanto é possível quanto necessário 'adaptar', 'ajustar', 'parametrizar' a intervenção educativa a alguma coisa que, 'na' substância-social, substância-neuronal ou substância-psicológica individual encerra, em última instância, as chaves do apre(e)nder. Mais ainda, assim definida, nem sequer alguns raciocínios psicanalíticos conseguem fugir dela. Por exemplo, não poucas vezes escutamos afirmações do tipo "a escola deve respeitar o desejo da ou de cada criança". Onde a ideia de 'se respeitar' veicula a miragem clássica da 'adaptação' a uma realidade prévia (classe social, neurônios, substancia psicológica, etc.), portanto, da necessidade de 'se conhecer o outro', de saber quem ele é, de quais seriam 'suas' condições, deficiências e 'seu' desejo antes de vir a lhe ensinar algo. A ilusão psicopedagógica condena a ter que conhecer de antemão o 'outro' da cena educativa para assim supostamente vir a adaptar a estratégia de intervenção. Em suma, trata-se da crença numa harmonia pré-estabelecida.

O império da ilusão psicopedagógica no ideário pedagógico é inversamente proporcional à força interpelativa do sonho de uma escola para todos. Este sonho norteou, bem como ainda norteia, os processos de escolarização massivos em vários países. São esses os países que conseguem introduzir a quase totalidade das crianças no mundo das letras e dos números. A título de exemplo, temos a Argentina dos finais do XIX embalada no sonho de Sarmiento, ${ }^{7}$ que passou a agonizar no pesadelo de Menen. Mas também, os países escandinavos da segunda metade do século XIX, a França das Leis de Jules Ferry, bem como a Cuba do calor revolucionário, que conseguiram em pouco tempo dar corpo a uma nação

\footnotetext{
${ }^{6}$ Lembro que, como já esclareci no prefacio ao livro "Figuras do infantil: a psicanálise na vida cotidiana com as crianças (LAJONQUIERE, 2009), a ilusão psicopedagógica atenta contra a própria constituição de um campo clinico de intervenção psicopedagógica. Então, impugnar a primeira não significa negar pertinência ao segundo.

7 "Sarmiento o sonhador continua a nos sonhar" proferiu o escritor Jorge Luis Borges por ocasião da clássica polêmica sobre o personagem da história argentina.
}

(C) ETD- Educação Temática Digital Campinas, SP $\quad$ v.21 $\quad$ n.2 $\quad$ p.297-315 abr./jun. 2019 
instruída. Quando esse sonho impera, curiosamente, os sonhadores não reclamam de 'crise na educação' alguma.

\section{DA ESCOLA E DOS PESADELOS RACISTAS}

O sonho de uma escola para todas as crianças tem a força de instalar num dado momento aquilo que antes não havia - um consenso nacional sobre a necessidade de possibilitar para todas as crianças, sem distinção alguma de nascimento e fortuna, o acesso a saberes transmissíveis. É um sonho de justiça que reconhece a palavra, e por sua vez, recohece à palavra adulta na escola, toda a sua dignidade educativa. No entanto, sonho algum se confunde com a realidade de todos os dias. A esta, sempre falta mais ou menos um pouco para ser de fato o ideal. Mas, sem os sonhos, é líquido e certo que a vida cotidiana não passaria de um interminável pesadelo. Por isso, a realidade escolar é diferente segundo as latitudes. Essas diferenças podem ser lidas como sendo a expressão do destino que the cabe em cada uma delas, nesse sonho tipicamente moderno e revolucionário de uma instrução pública e universal.

Talvez, uma das singularidades da escolarização no Brasil seja o fato da ilusão psicopedagógica imperar desde sempre no campo pedagógico. Já quando da nascente República pensava-se que, se a escola que havia não era uma escola, visto a magnitude dos ditos fracassos, isso obedecia ao fato das crianças brasileiras serem refratárias aos saberes ensinados, portanto, as crianças eram ou decididamente incapazes ou merecedoras de uma pedagogia diferente. Essa ideia exprime à sua maneira o pesadelo racista-escravocrata e desde então ela vaga no tempo assombrando a experiência escolar, fazendo ouvidos moucos à declaração, mais que centenária, da abolição. Pensar que alguém é em princípio refratário aos saberes em virtude da tal ideia de raça é simplesmente um pensamento racista. Foi em seu nome que a maior parte da população na colônia e no Império fora privada da liberdade, portanto, da possibilidade de se lançar em nome próprio à palavra, bem como de dispor do próprio corpo. No entanto, há também algo de racismo embutido na ideia de que alguém é refratário ao saber por conta, por exemplo, do sexo biológico que porta, ou de ter nascido economicamente pobre, ou de morar em tal bairro, ou de proferir uma determinada religião.

Nos anos de 1930, intelectuais brasileiros insuspeitos e pioneiros abraçaram a causa de uma nova educação escolar. Movimento em si mesmo louvável. Mais ainda em se considerando que nenhuma dessas personalidades públicas acabou entrando nas páginas policiais, como não poucos gestores de merenda escolar ou de material didático de nossos dias. No entanto, os pioneiros da escola nova cometeram o erro de pensar que aquilo que faltava à escola brasileira era uma pedagogia que se preze científica, e dessa forma acabaram, sem querer, mantendo incólume o pesadelo racista que pretendiam honestamente superar. Mais tarde, nos anos de ditadura militar, foi a vez de se pensar que havia na população mirim,

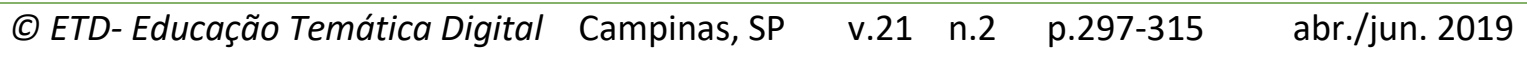


crianças carentes de cultura, de saberes, de práticas, de capacidades, em suma, crianças carentes para tirarem proveito da experiência escolar por uma série de razões e portanto, essas carências deviam ser previamente compensadas de forma metódica, para que, enfim, pudessem aprender aquilo que Ihes seria ensinado na escola. Pois, é aqui reencontramos reconvertido em linguagem atual o velho racismo da época de quando ainda se falava em termos de raça. Porém, não se tratava mais de segregar explicitamente o 'outro' na porta da escola, mas de interpelá-lo, de colocar esse 'outro' no lugar de carente, do qual seja quase impossível sair, ou que ele mesmo seja levado a se autodeclarar carente de mais não poder. Já mais tarde, na década de noventa, não se tratava mais de pensar em carências a serem compensadas. Todas as crianças passaram no papel a serem passíveis de apreender, porém, sempre e quando a transmissão escolar dos saberes obedecesse à uma série de novos parâmetros científicos de inspiração psicológica ajustados à realidade infantil. Em suma, até agora não vingou no Brasil a ideia moderna e revolucionária de que toda criança, pelo simples fato de partilhar com o adulto o campo da palavra e da linguagem, é candidata a apre(e)nder saberes acumulados pela humanidade e passíveis de serem ensinados na escola.

Os sistemas escolares que vigaram, embora com todos os defeitos que se possam imaginar, sempre merecedores de superação no decorrer do tempo, foram embaladas pelo sonho de uma instrução pública universal e irrestrita. O desdobramento desse endereçamento a todas as crianças é sinfônico à vida política de uma nação, portanto, está sempre sujeito à luta política que tenta fazer pender a história para um lado ou para outro. Que o sonho tenha emplacado nas latitudes em que se fez não deve ter sido certamente coisa fácil, pois, progresso societário algum do sonho de justiça acaba caindo de maduro como se diz. Mas uma coisa é certa, na medida em que o sonho de uma escola para todos vinga e permanece, então, a escola funciona. Nesse sentido, é possível fazer a hipótese de que foi esse singelo sonho que animou o passageiro élan escolar vivenciado em Porto Alegre quando do primeiro governo municipal do PT (Partido dos Trabalhadores), para além dos efeitos renovadores aportados pela racionalização pedagógica autodenominada "construtivismo pós-piagetiano". Porém, se o sonho não é mais sonhado, então, as escolas e as crianças se ressentem, enquanto a nação vira novamente oligárquica. Nesse caso, o exemplo emblemático do desmonte de uma escola, na contramão da história, é a reforma psicopedagógica promovida pelo governo reacionário e corrupto de Carlos Menen na Argentina.

O sonho de uma escola para todos perde eficácia com o tempo. Para que todo sonho continue a produzir efeitos, ele deve ser (re)sonhado. E 'isso' dá trabalho! ${ }^{8}$ Quando ele se

\footnotetext{
${ }^{8}$ Na psicanálise em língua portuguesa o termo Isso refere-se ao inconsciente. A afirmação alude à exigência de trabalho psíquico e discursivo inerente ao desejo inconsciente.
}

(C) ETD- Educação Temática Digital Campinas, SP $\quad$ v.21 $\quad$ n.2 $\quad$ p.297-315 abr./jun. 2019 
esgota, ficam sem vida os ouropéis imaginários do discurso pedagógico. É o caso da situação escolar atual na França. A carcaça pedagógica em torno dos saberes escolares é incapaz hoje de empolgar massivamente crianças e adultos como outrora. Não mais tomados no sonho como antes, os adultos passam a endereçar às crianças uma palavra educativa natimorta. Estas últimas, por sua vez, tampouco se lançam como outrora a apre(e)nder os conhecimentos ensinados, já não mais significantes de um desejo outro além do gozo pedagógico. $O$ discurso pedagógico hegemônico francês ainda não remanejado pelo império da ilusão psicopedagógica, como no caso do Brasil e da Argentina, passa assim a pecar por excesso. Como a ilusão psicopedagógica ocupa um lugar marginal no ideário francês, perante toda nova constatação de que o resultado educativo não é o almejado, o discurso pedagógico hegemônico repete a dose de apresentação mecânica dos saberes, convicto de que esse 'ensino' per se animará o apre(e)nder infantil, não conseguindo entrever que a chave do processo não passa pela mostra dos conhecimentos, mas pelo desejo em causa no ensino. Assim, ele acaba também contribuindo com o aumento do contingente de crianças excursionistas à deriva em terras polares - lembrando o suspicaz comentário freudiano - e as passa a chamar de décrocheurs.

\section{DA INTERPELAÇÃO PEDAGÓGICA E DA DIGNIDADE DE UMA ESCOLA JUSTA}

A julgar pela quantidade e complexidade das diretivas a serem seguidas na hora de ensinar os saberes escolares às crianças, apre(e)ndê-los pareceria ser hoje um processo muito complexo. Que essa ideia, derivada do império da ilusão psicopedagógica, me pareça pessoalmente exagerada não quer dizer tampouco que apre(e)nder, e mais ainda fazê-lo no contexto escolar, seja dado de bandeja a uma criança.

Costumo imaginar que, uma vez que aprendemos a falar, ou que nós 'nos apreendemos' à palavra - nós nos seguramos nela - não deveria haver nada muito mais complicado na vida. Aprender a falar uma língua qualquer, entranha, para todo bebê, um trabalho psíquico decisivo. Costumamos inquirir alguém nos seguintes termos: "de onde fala?" ou "como é que me fala nesses termos?", ou seja, "de que lugar me fala isso?". Nesse sentido, termos que falar implica na conquista de um lugar de palavra ou de enunciação num discurso. Do balbucio à utilização do pronome pessoal 'Eu' - "Eu tenho fome" -, tendo passado pela referência a si mesmo se valendo da terceira pessoa - "Pedrinho tem fome" -, um bebê lançado à palavra deixa, logo mais, de ser infans, transformando-se numa criança pequena capaz de brincar de que 'era' o grande que 'ainda não é', mas que 'espera vir a ser' - "Vamos brincar de que éramos bombeiros?". Essa transformação, que só um ser humano pode experimentar, articula-se no interior do campo da palavra e da linguagem entranhando em si a conquista de um lugar para si no tecido discursivo. Se tal façanha acabou sendo possível o foi porque, o pequeno sujeito suportou experimentar, em carne própria, o

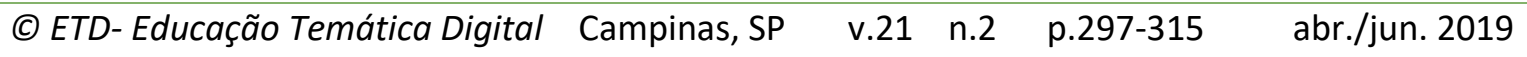


desdobrar desse processo discursivo inconsciente, que é a operação inconsciente de "identificação" ao $S_{1}$ (significante um ou mestre), recortado do campo do Outro com a sua consequente remissão a um $\mathrm{S}_{2}$ (significante dois ou saber), que o relança à operação de enunciação, conforme o raciocínio psicanalítico lacaniano. Mais ainda, o bebê lança-se à experiência, embalado na relação ao outro primordial materno, em função de ser portado pela "apetência simbólica" (CULLERE-CRESPIN, 2007) - o nome no simbólico para a orfandade biológica radical própria à espécie sapiens.

O lugar de sujeito da palavra no discurso não resulta nem da maturação biológica nem da 'imitação' de comportamentos viabilizada por capacidade biológica primitiva alguma. A 'identificação' que está em causa comporta um duplo e mesmo movimento: o fading do sujeito pela colagem num traço do Outro, a alienação no sentido, bem como a separação ou perda do sentido previamente ganho por conta do recalcamento primário do $S_{1}$ instaurador da remissão significante (LACAN, 1968-1969). Que a 'identificação simbólica' acabe vingando, pois, nada a garante a priori, depende do entrecruzamento de duas condições igualmente necessárias: por um lado, que o bebê suporte experimentar a tensão imaginaria com o 'Eu ideal' e, por outro, que o adulto seja capaz de dar testemunho do desejo. Em outras palavras, o resultado da conquista de um lugar de sujeito no discurso deve ser colocado no crédito tanto da criança quanto do adulto, na razão de $50 \%$ cada, ou seja, trata-se de um comprometimento indeterminado, mas que, na contabilidade feita pela e numa psicanálise, será creditada na coluna 'escolha do sujeito', que, não tendo idade, não é criança nem adulto. Já ao adulto, cabe nesta empreita, conforme o esquema ótico proposto por Lacan (19531954) para pensar a experiência especular, 'botar o olho' na posição certa, ou seja, endereçar a palavra ao bebê numa posição tal que o testemunho do desejo que anima o ato educativo seja possível. Se o adulto não conseguir sustentar esse ato testemunhal, a educação primordial vira um fato de difícil acontecimento. Isto é, ela não se torna impossível, mas o trabalho a ser realizado pela criança requer de uma chance suplementar.

Valermo-nos de a expressão 'endereçar a palavra a uma criança' 'é dizer muito mais que o simples fato de se expor uma criança a uma linguagem oral. É justamente por isso que nenhum bebê conquista lugar algum no discurso pelo simples fato de ser exposto, horas a fio, frente à TV ou ao rádio. $O$ adulto deve se endereçar à criança, deve 'falar com ela'. Pode ser que o adulto não fale uma língua oral, pode ser que o bebê não consiga ouvir, nem ver o adulto - lembremos a pequena cega e surda Helen Keller - mas isso não impede o adulto de se endereçar à criança, nem a esta de saber-se reconhecida na sua sujeição ao desejo (LAJONQUIERE, 2009; 2017). O que conta então na educação primordial é o endereçamento

\footnotetext{
${ }^{9}$ Endereçar a palavra a uma criança não deve ser confundido com o fato costumeiro de falar cientificamente d'A Criança (LAJONQUIERE, 2008, 2009).
}

(C) ETD- Educação Temática Digital Campinas, SP $\quad$ v.21 n.2 $\quad$ p.297-315 abr./jun. 2019


adulto - tocar mais, ou tocar menos, falar 'sim', mas também às vezes 'não', dar de comer, não dar mais, mirar fixamente, seriamente, mirar o horizonte, etc, testemunho da castração em causa na mesmíssima educação, que possibilitará à criança deparar-se com o "Chez vuoi?” esse 'outro' radicalmente 'outro' que aí está (LACAN, 1957-1958). Ou, conforme as duas notas remitidas por Lacan à Jenny Aubry, em outubro de 1969, o que conta é a educação primordial entranhar em si uma relação a um desejo que não seja anônimo (LACAN, 1986). Em suma, é o desejo que eleva essa espécie de maré interativa bebê-mundo adulto, à categoria de linguagem ou de 'função significante' capaz de possibilitar a sujeição do bebê a um lugar no discurso.

Apre(e)nder os números, a ortografia, a geografia, a física, ou o que for, entranha uma mesma e única façanha - aquela de conquistar um lugar de palavra no interior de uma língua qualquer. Por exemplo, aquele que aprende a matemática passa a falar 'matematiquês'. Em certo sentido, apre(e)nder saberes diversos é como aprender a se dizer numa língua outra que não a primordial ou materna. A educação escolar continua, prolonga, mas também inscreve ou escreve uma diferença na educação precipitada primordialmente em braços mais ou menos familiares. Os políticos e pedagogos que promoveram a escolarização pública, laica e massiva do final do século XIX alguma coisa suspeitavam nesse sentido, embora nunca tenham lido a alocução de Freud por ocasião dos festejos do quinquagésimo aniversário da fundação do colégio secundário que ele frequentara em Viena (FREUD, 1914). Sabiam que se tratava de fazer com que as crianças tomassem distância das tradições e idiossincrasias familiares e, ao mesmo tempo, supunham que, para bancarem o trabalho escolar, elas deviam já dispor de certas condições pessoais. Não por acaso, a entrada na escola foi estabelecida de forma geral em torno dos seis anos, não muito mais tarde, para não se perder tempo, mas tampouco mais cedo, pois, a criança se veria confrontada com uma demanda escolar desproporcionada. Sem saber, esses pedagogos de antanho sabiam que, em torno dessa idade, algo muda na qualidade da circulação social de uma criança. Após mais de um século de psicanálise, tais mudanças devem ser creditadas à passagem mais ou menos bem-sucedida pela experiência edipiana.

A criança que tenha se encaminhado, com maior ou menor sucesso, na elaboração infantil de uma posição neurótica no campo da palavra e da linguagem tem todas as chances a seu favor para emplacar o jogo escolar. A demanda escolar interpela a criança como aluno. O fato 'se fazer aluno' - ou de brincar de ser o aluno que não é, pois trata-se de fato de uma criança - na medida em que 'aí', nesse lugar que o mundo adulto diz à criança que deve advir para vir a ser grande um dia, pressupõe uma criança capaz de bancar o jogo, de 'fazer de brincadeira'. A escola do fim do século XIX foi inventada para fazer das crianças alunos capazes de se prepararem para entrar, chegado o momento, no mundo letrado dos grandes. A transformação numa pessoa grande resulta de uma primeira em aluno. Ou seja, nas

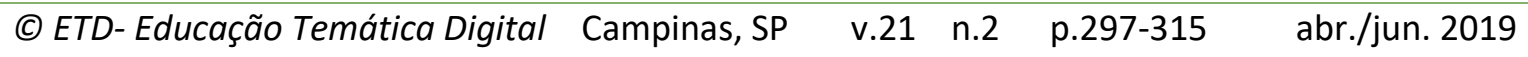


sociedades escolarizadas não se passa de criança à pessoa grande. A demanda escolar entranha em si mesma a interpelação da criança como aluno. A escola pede para a criança fazer de conta que é um aluno no interior do cenário escolar. Fora do perímetro ou do horário escolar, a pedagogia de antanho sabia que criança voltava a ser o que era - uma criança, filho(a) de...

A escola expande o horizonte existencial de uma criança. Os pedagogos tomados no sonho de uma mesma e única escolarização para todos - para patrícios e imigrantes, pobres e ricos, brancos e negros, fiéis e agnósticos, citadinos e camponeses - pretendiam que a criança tivesse a chance de não ficar presa às fronteiras familiares, isto é, àquelas impostas pelo nascimento e idiossincrasias familiares. Por um lado, a aprendizagem dos conhecimentos ensinados era o passaporte para outros mundos; por outro, o fato de participar da experiência junto a outros, não-familiares, era também parte dessa viagem a um outro mundo. Nesse sentido, é possível - à distancia - levantar a hipótese de que, se Sigmund Freud não tivesse tirado proveito de ter frequentado à escola em Viena, então, nunca teria ido à Roma e se dado de cara com Moisés na Basilica di Santo Pietro in Vincoli. Se assim fosse, então, ele nunca teria vindo a ser Freud - o pai inventor da psicanálise. O sonho de uma escola para todos instaurava as chances de bons encontros. Nesse mesmo sentido, perguntamo-nos: e se o pequeno Albert Camus não tivesse ido à escola na Argélia francesa? Pois, é o próprio Prêmio Nobel de Literatura de 1957 respondeu à pergunta. Afirmou na carta que endereçou, logo após receber a notícia de ter sido laureado, ao professor da escola que frequentou em Argel - O Senhor Germain - que, se não tivesse sido por essa "mão afetuosa estendida ao garoto pobre", órfão de pai e filho de mãe analfabeta, que ele foi quando pequeno, nunca teria chegado aonde chegou (LAJONQUIERE, 2013, p. 67). A escola tomada no sonho de uma escola para todos instaurava uma diferença na primeira educação familiar. Expandindo o horizonte existencial, possibilitava a cada criança se posicionar diferentemente na dramática familiar, e assim, focar o desejo na travessia rumo a dizer a que veio na vida dos homens.

A criança supõe que o mundo adulto lhe esconde o saber ser grande que falta no real. Assim, tomada na esperança de vir a tê-lo quando grande, não lhe cabe mais que apre(e)nder aquilo que, em doses mais ou menos homeopáticas, a escola coloca à sua disposição. Assim sendo, a criança aprende na escola não por efeito da maturação, nem graças à imitação ou repetição de comportamentos, mas por efeito da sujeição a um desejo que não seja anônimo. Sobre este, ela pretende 'saber', mas, como tal coisa é de fato impossível, então a criança acaba se lançando ao 'conhecimento' desses outros mundos possíveis que a escola faz existir no horizonte ${ }^{10}$. Não todas as crianças tiram bom proveito da experiência escolar. Cada uma

\footnotetext{
${ }^{10}$ Sobre a diferença entre a ordem dos 'Conhecimentos' e a do 'Saber' no interior do campo dos estudos psicanalíticos na educação consultar LAJONQUIERE (1993).
}

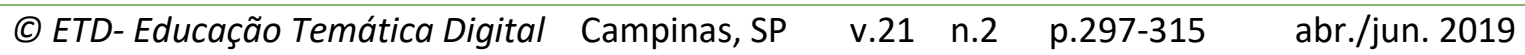


revela ser uma. E isso vale para qualquer experiência humana, não todos tiram proveito de uma viagem de férias, de um jantar com amigos ou do matrimônio. Mas isso não é da conta do estado. A questão é, até que ponto a demanda veiculada pelo sistema escolar interpela a criança como um aluno, tanto dotado de inteligência quanto de interesse em apre(e)nder os saberes veiculados, da mesma forma que uma mãe é capaz de se endereçar a seu bebê numa posição tal que instaura as chances da criança engatar no discurso - embora o desejo materno tampouco seja obviamente conta de estado algum!

O sonho de uma escola para todos criou as condições para que a imensa maioria das crianças tirasse proveito da experiência escolar, para além do inelutável ponto cego de todo sistema pedagógico. As condições estão dadas em função de uma série de fatos: fato de que os salários são dignos, fato de que o governo e os pais das crianças têm confiança nos professores, fato de que há escolas para todos, fato de que não há máfia da merenda, fato de que os professores tiram algum proveito existencial da experiência de serem professores, etc. A realidade dos fatos não é aquela dos sonhos, mas é certo também que, um sonho não se confunde com uma certeza delirante. Por exemplo, lembremos que a desolação do holocausto fez com que o sonho de Deus abandonasse mais de uma alma religiosa. Nesse sentido, na Argentina e no Brasil, fica um tanto difícil de segurar-se no sonho de uma escola para todos. Na França resulta ser ainda uma empresa plausível, embora não na mesma proporção que antanho e sem garantia alguma de que o futuro não reserve para a escola e as crianças um destino funesto.

Quando os sistemas escolares não são mais, ou nunca foram, sonhados pelo sonho de uma escola para todos virem a ser igualmente grandes um dia, então, a demanda escolar não instaura brincadeira alguma para a criança. Assim sendo, o dispositivo escolar perde sua potestade simbolígena de interpelar a criança em aluno. As chances diminuem, e as crianças são forçadas a trabalhar em dobro para situar no horizonte um desejo como norte. Ou, em outras palavras, perdem a direção da travessia, pois, se embaralham com um mapa que não possibilita focar o norte no horizonte pedagógico. A dita crise na educação não é um problema de falta de métodos adequados para transmitir os saberes ou gerir a socialização infantil, conforme apregoa o discurso (psico)pedagógico hegemônico na Argentina e no Brasil, mas de justiça. Sem o sonho justo de uma escola para todos, não há escola para ninguém, embora possa haver simulacro escolar para alguns poucos. É em nome de um moderno sonho de justiça que os saberes escolares são suscetíveis de ser transmitidos. É em seu nome que a escola é suscetível de dar chances a uma criança de vir a se dizer no mundo dos homens de outra forma diferente daquela suposta quando chegara à vida.

\begin{tabular}{|c|}
\hline (c) \\
\hline
\end{tabular}




\section{REFERÊNCIAS}

ALTHUSSER, Louis. Idéologie et appareils idéologiques d'État. In: ALTHUSSER, Louis.

Positions. Paris Éditions Sociales, 1976. p. 67-125.

ARENDT, Hannah. La crise de l'éducation. Paris: Gallimard, 1972 [1958].

BLAIS, Marie-Claude; GAUCHET, Marcel; OTTAVI, Dominique. Transmettre, apprendre. Paris: Editions Stock, [19--].

CULLERE-CRESPIN, Graciela. L'épopée symbolique du nouveau-né. Toulouse: Erès, 2010.

FREUD, Sigmund. Algumas Reflexões Sobre a Psicologia do Escolar. In: FREUD, Sigmund. Edição Standard Brasileira das Obras Psicológicas Completas de Sigmund Freud. Volume 13. Rio de Janeiro: Imago, 1990 [1914]. p. 285-289.

FREUD, Sigmund. O futuro de uma ilusão. In: FREUD, Sigmund. Edição Standard Brasileira das Obras Psicológicas Completas de Sigmund Freud. Volume 21. Rio de Janeiro: Imago Editora, 1990 [1927]. p. 15-79.

FREUD, Sigmund. O mal-estar na civilização. In: FREUD, Sigmund. Edição Standard Brasileira das Obras Psicológicas Completas de Sigmund Freud. Volume 21. Rio de Janeiro: Imago Editora, 1990 [1929]. p. 81-177.

LACAN, Jacques. Deux notes sur l'enfant. Ornicar? n. 37, p. 13-14, 1986 [1969].

LACAN, Jacques. Le Séminaire Livre I. Paris: Seuil, 1975 [1953-1954].

LACAN, Jacques. Le Séminaire Livre V. Paris: Seuil, 1975 [1957-1958].

LACAN, Jacques. Le Séminaire Livre XVI. Paris: Seuil, 2006 [1968-1969].

LAJONQUIERE, Leandro (de). De Piaget a Freud. Petrópolis: Vozes, 2009 [1993].

LAJONQUIERE, Leandro (de). Dos erros e em especial daquele de renunciar à educação.

Estilos da Clínica, n. 2, p. 26-43, 1997. Disponível em:

https://www.revistas.usp.br/estic/issue/view/4984. Acesso em: 22 mar. 2019.

LAJONQUIERE, Leandro (de). Infância e ilusão (psico)pedagógica. Petrópolis: Vozes, 1999.

LAJONQUIERE, Leandro (de) Niños extraños. En Cursiva. Revista Temática (Buenos Aires). v.4, p. 41- 46, abr. 2008.

LAJONQUIERE, Leandro (de). De como jogamos fora a criança com a agua suja do amorodio. In: COLOQUIO INTERNACIONAL DO LEPSI, 7., 2008, São Paulo. Anais... An 7 Col. LEPSI IP/FEUSP, 2009. Disponível em:

http://www.proceedings.scielo.br/scielo.php?script=sci arttext\&pid=MSC00000000320080 00100009\&Ing=pt\&nrm=iso\&tlng=pt. Acesso em: 22 mar. 2019.

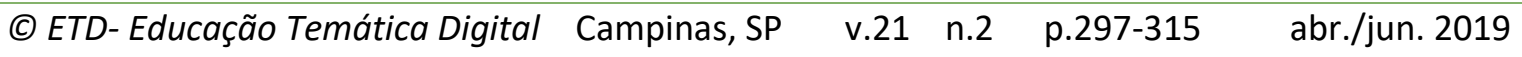


LAJONQUIERE, Leandro (de). Figuras do infantil. Petrópolis: Vozes, 2009.

LAJONQUIERE, Leandro (de). A mestria da palavra e a formação de professores. Educação \& Realidade, v. 36, n. 3, p. 849-865, 2011. Disponível em:

https://seer.ufrgs.br/educacaoerealidade/article/view/13316. Acesso em: 22 mar. 2019.

LAJONQUIERE, Leandro (de). A palavra e as condições da educação escolar. Educação \& Realidade, v. 38, n. 2, p. 455-469, abr./jun. 2013. Disponível em:

http://dx.doi.org/10.1590/S2175-62362013000200006. Acesso em: 22 mar. 2019.

LAJONQUIERE, Leandro (de). O selvagem poderia ter falado? Ou das condições estruturais de uma educação. In: BANKS-LEITE, Luci (Org.) O Garoto Selvagem e o Dr. Jean Itard.

História e diálogos contemporâneos. Campinas: Mercado de Letras, 2017. p. 79-100.

LEVI-STRAUSS, Claude. Antropologie structurale. Paris: Plon, 1958.

\section{AGRADECIMENTOS}

Agradeço às doutorandas Caroline e Andressa que em diversos momentos contribuíram com seus conhecimentos sobre a gramática portuguesa.

Revisão gramatical realizada por:

Andressa Mattos Salgado Sampaio:

E-mail: andressa salgado@usp.br

Caroline Fanizzi:

E-mail: caroline.fanizzi@gmail.com 